\section{LIDERANÇA TRANSFORMACIONAL E TRANSACIONAL: uma revisão bibliográfica narrativa}

\section{TRANSFORMATIONAL E TRANSACTIONAL LEADERSHIP: a narrative bibliography review}

\author{
Érica de Souza Soardo ${ }^{1}$ \\ Júlia Pacheco Fanton ${ }^{2}$ \\ Edward Goulart Júnior ${ }^{3}$
}

\begin{abstract}
Resumo
Visando compreender como se dá a relação líderliderado nos tipos de liderança transacional e transformacional e seus resultados, o objetivo deste estudo foi apresentar uma revisão bibliográfica narrativa acerca do assunto e verificar os contextos nos quais esses tipos de liderança estão sendo utilizados e seus impactos. A coleta de dados partiu da busca dos bancos de dados: Literatura LatinoAmericana e do Caribe em Ciências da Saúde (LILACS), Scientific Electronic Library Online (SCIELO), Dialnet e Portal Regional da BVS, considerando os descritores: "liderança transformacional", "liderança transacional", "liderança transacional e transformacional". Considerou-se a data das publicações, entre o período 2008-2019, e a presença dos descritores no título dos artigos. Foram encontrados 31 textos: 10 em português, 14 em espanhol e seis em inglês. Após a seleção dos artigos foram realizadas leituras exploratórias para maior compreensão acerca dos assuntos definidos e exploração do material coletado.
\end{abstract}

Palavras-chave: estilo de liderança. liderança transacional;.liderança transformacional.

\begin{abstract}
To understand how the leader-fellow relation occurs in the transactional and transformational kinds of leadership, as well as their results, this study aimed to show a bibliography review about this issue and verify the contexts in which such kind of leadership has been applied and their impacts. Data collection was performed on the following databases: Latin American and Caribbean Health Sciences Literature (LILACS), Scientific Electronic Library Online (SCIELO), Dialnet, and BVS Regional Portal, considering these descriptors: "transformational leadership", "transactional leadership", "transactional and transformational leadership". The date of these publications, from 2008 to 2019, and the presence of these descriptors in their titles were considered. 31 texts were found: 10 in Portuguese, 14 in Spanish and 6 in English. After this selection, an exploratory reading was performed for a better understanding of the defined subjects and the exploration of the collected material.
\end{abstract}

Keywords: leadership style. transactional leadership. transformational leadership.

\footnotetext{
${ }^{1}$ Aluna de Graduação do Curso de Psicologia da Unesp, campus de Bauru. E-mail: ericasoardo@hotmail.com

${ }^{2}$ Aluna de Graduação do Curso de Psicologia da Unesp, campus de Bauru. E-mail: juliafanton18@gmail.com

${ }^{3}$ Professor Assistente Doutor do Departamento de Psicologia da Faculdade de Ciências da Unesp, campus de Bauru. Email: edward.goulart@unesp.br
}

Artigo recebido em: 20 de maio de 2020. Artigo aceito em 07 de janeiro de 2021. 


\section{Introdução}

Ao longo do tempo, o conceito de liderança foi se transformando a luz de diferentes abordagens e pressupostos até os tempos atuais. Entre esses conceitos e abordagens contemporâneas, encontram-se as lideranças transformacionais e transacionais. Segundo da Silva et al. (2013), o conceito de liderança transformacional foi trazido por Burns, em 1978, embasado na teoria da hierarquia das necessidades de Maslow e nas ideias de Kolberg sobre o desenvolvimento moral (BAILEY; AXELROD, 2001; DVIR et al., 2002) e influenciado pela crise política, econômica e social ideológica nos Estados Unidos (CALAÇA; VIZEU, 2015). Foi Bass, no entanto, que, em 1985, desenvolveu uma construção conceitual que permitiu a sistematização necessária para a realização de pesquisas empíricas sobre liderança transformacional, por partir de inferências mais diretas acerca do vínculo entre liderança e desempenho coletivo (VIZEU, 2011; SILVA BARRETO et al., 2013). Já o termo liderança transacional surgiu quando Bass e Avolio (1997) propuseram três estilos de liderança, sendo eles liderança transacional, liderança transformacional e laissez-faire.

Nesse sentido, de acordo da Silva et al. (2013), a liderança transacional é pautada em relações contratuais explícitas ou implícitas, ou seja, as atribuições, condições de empregabilidade, códigos disciplinares e política de bonificações são bem definidas, o que, segundo Vizeu (2011), Burns define como um estilo de liderança que baseia suas ações na legitimidade e autoridade formais, podendo ser entendido como um processo de troca entre líderes e liderados, de modo que o líder enfatiza para seus liderados sua capacidade de atender suas necessidades particulares, se apresentando como alguém capaz de recompensar ou punir seus seguidores, a partir de regras e normas pré-estabelecidas. Nesse sentido, Vizeu (2011) explica que a recompensa se destina àqueles que cumpriram as tarefas desejadas e a punição, àqueles que não cumpriram seus objetivos ou que se comportaram de modo indesejável. O autor explica ainda que o processo da liderança transacional pode ser entendido como um esforço do líder em satisfazer os desejos individuais, em troca do esforço que os liderados terão para cumprir determinados objetivos. Para Bass e Avolio (1993), Kent, Crotts e Azziz (2011) e Schilling e Schilling (2008), a liderança transacional pode ser dividida em recompensa contingente, oriunda do esforço do liderado e estipulada a partir de suas necessidades e gerenciamento por exceção, seja ele ativo, quando o líder espera que o

Revista Eletrônica Gestão e Serviços v.11, n. 2, pp. 3098 - 3129, Julho/Dezembro 2020. ISSN Online: 2177-7284 e-mail: regs@metodista.br 


\section{SOARDO; FANTON; JUNIOR}

erro ocorra para corrigi-lo, ou passivo, em caso de intervenção somente quando o erro sobressai. Vizeu (2011) ressalta que, as necessidades geralmente satisfeitas neste contexto são as mais baixas da hierarquia de Maslow, ou seja, as necessidades fisiológicas, de segurança, sociais e de estima, como salários, promoção e melhoria da satisfação profissional (VIZEU, 2011). Destarte, líderes transacionais são, em resumo, negociadores e alocadores de recursos, os compromissos com seus subordinados são de curto prazo e eles não tendem a estimular seus subordinados a inovar ou arriscar (BASS; AVOLIO, 1993; OGBONNA; HARRIS, 2000).

No tocante ao tipo de liderança transformacional, García-Guiu et al. (2016) argumentam que o foco do líder transformacional consiste no desenvolvimento, no envolvimento e na transformação de sua equipe de trabalho, por meio de estímulos intelectuais, da comunicação inspiradora das expectativas, do fornecimento de visão, da expectativa de desempenho e da valorização das atividades. Para os autores, o líder nesse cenário é um agente de mudanças, a partir dos quatro domínios da liderança transformacional identificados por Avolio, Bass e Jung (1999), sendo eles: influência nos ideais, motivação inspiradora, estimulação intelectual e consideração individual. A influência nos ideais representa, segundo proposições de Godoy e Bresó (2013) e Fernandes, Siqueira e Vieira (2014), a capacidade de influenciar seguidores por meio de um ideal, emergindo a transcendência da orientação para os interesses do grupo. Já a motivação inspiradora, de acordo com os autores, é a capacidade do líder em articular com o grupo o como um futuro desejável pode ser alcançado, apresentando altos padrões de desempenho, demonstrando determinação e confiança. A terceira característica, estimulação intelectual, é descrita por eles como a capacidade que o líder tem de provocar a reflexão, de encorajar seus liderados a abordar problemas antigos e familiarizados de novas formas, a partir de novas perspectivas, promovendo a inovação e a criatividade. Por fim, a consideração individual diz respeito ao desenvolvimento e crescimento dos seguidores propriamente dito, levando em conta as particularidades de cada um, a fim de buscar cada vez mais desafios e a promoção do autodesenvolvimento, de modo que pode se manifestar quando o líder delega tarefas como oportunidades de crescimento (GODOY; BRESÓ, 2013).

Tendo em vista o exposto, uma revisão de literatura acerca da liderança transacional e transformacional se justifica pela melhor compreensão de como se dá a relação líder-liderado nesses tipos de liderança e seus resultados para ambos e para as 


\section{SOARDO; FANTON; JUNIOR}

organizações de trabalho. Justifica-se também pela escassez de artigos articulando esses assuntos, considerando a importância cada vez maior que o trabalho exerce na vida dos indivíduos na contemporaneidade. Assim, o presente estudo tem como objetivo apresentar uma revisão bibliográfica narrativa acerca do assunto e verificar os contextos nos quais esses tipos de liderança estão sendo colocados em prática e como os tem afetado.

\section{MÉTODO}

A coleta de dados, executada entre novembro de 2018 e dezembro de 2019, partiu da busca dos seguintes bancos de dados: publicações da Literatura LatinoAmericana e do Caribe em Ciências da Saúde (LILACS), da Scientific Eletrônic Library Online (SCIELO), da Dialnet e do Portal Regional da BVS, considerando os seguintes descritores: "liderança transformacional", "liderança transacional", "liderança transacional e transformacional". Apesar dos temas terem sido pesquisados em português, a busca indicou alguns artigos em inglês e em espanhol, os quais foram incorporados à pesquisa, uma vez que a quantidade de artigos em português que abordavam os temas em questão não era considerável.

Como critério de inclusão, se considerou a data das publicações, entre os anos de 2008 até 2019, e a presença dos descritores no título dos artigos. Assim, foram encontrados 31 textos, sendo 10 em português, 14 em espanhol e 6 na língua inglesa. Após a seleção de artigos, conforme os critérios de inclusão definidos, foram realizadas: (a) uma leitura exploratória para maior compreensão acerca dos assuntos definidos e exploração do material coletado; (b) a leitura seletiva, para uma coleta de dados mais definida; (c) a leitura interpretativa e (d) a construção da redação.

\section{RESULTADOS: TÓPICOS PRINCIPAIS OBTIDOS}

Os conteúdos dos textos incluídos nesta revisão bibliográfica narrativa, foram divididos em sete categorias, a partir das quais os resultados serão apresentados. São elas: Análises sobre a liderança transformacional; Validação de instrumentos; Perfil de liderança; Estilos de liderança e variáveis relacionadas; Estilos de liderança e educação; Estilos de liderança e área da saúde; e Estilos de liderança e áreas afins. 


\section{a) Análises sobre a liderança transformacional}

Calaça e Vizeu (2015), à luz da hermenêutica de profundidade, analisaram a teoria da liderança transformacional, revelando pontos obscuros no empréstimo conceitual feito pelos pesquisadores de liderança da área organizacional. Os autores abordam, para tanto, a época e o contexto dentro dos quais Burns desenvolveu sua teoria e a forma pela qual Bass a transportou para o contexto organizacional. Como conclusão, destacam que o ponto central da teoria é o desenvolvimento moral e o afastamento na relação utilitária entre gestores e subordinados, o que é reforçado pelos exemplos usados pelo autor da própria teoria: quase sempre relacionados a liderança no contexto político e nos movimentos sociais.

Outro estudo elaborado por Vizeu (2011) analisa as ideias sobre a liderança transformacional à luz das referências teóricas da ação comunicativa, verificando as possibilidades que essa proposta de liderança assume quando avaliada por uma teoria de cunho crítico e de orientação ontológica interpretativista. Segundo o autor, a ideia de influência defendida pela liderança transformacional pode comprometer a reciprocidade, elemento essencial para um espaço de fala livre, que, para se estabelecer, precisaria advir de um modelo de liderança transformacional desvinculado da ideia de autoridade formal.

De cunho mais pragmático, Cruz-Ortiz, Salanova e Martínez (2013) integraram investigações recentes que buscavam compreender o estado atual da questão e linhas de estudo futuras, apontando a liderança transformacional como um recurso indispensável para potencializar e formar dentro de organizações, a chave para compreender a relação líder-seguidor e como um aspecto decisivo para alcançar resultados organizacionais de excelência. Os trabalhos revisados pelos autores se ocuparam dos antecedentes da liderança transformacional e seus resultados - tanto para os trabalhadores, quanto para a organização -, identificando variáveis intervenientes no processo de liderança. A revisão constatou que poucos trabalhos trataram de intervenções dirigidas a otimizar a liderança transformacional e que as organizações não precisam apenas de líderes para motivar os indivíduos, mas devem considerar a equipe de trabalho em conjunto.

\section{b) Validação de instrumentos}

Rozo-Mogollón e Abaunza-González (2010) aplicaram pela primeira vez na 


\section{SOARDO; FANTON; JUNIOR}

Colômbia o Questionário Multifatorial de Liderança (MLQ-5X), desenvolvido por Bass e Avolio (2004). Os autores calcularam o alfa de Cronbach para determinar sua confiabilidade e utilizaram medidas de porcentagens e dispersão para descrever, respectivamente, as variáveis nominais, as variáveis ordinais e as frequências da população. Para a análise do instrumento, eles estabeleceram o escore de cada uma das dimensões - avaliada por item - e realizaram uma descrição do grupo da amostra, em relação às propriedades obtidas nas variáveis dos tipos de liderança levantadas. Por fim, fizeram uma análise de correspondência múltipla para determinar a relação entre as variáveis sociodemográficas e laborais e os tipos de liderança, constatando que o MLQ$5 \mathrm{X}$ é efetivo para mensuração de liderança transacional e transformacional.

Beveren et al. (2017), com o objetivo de adequar e validar a Escala Global de Liderança Transformacional (GTL) para a língua portuguesa, testaram e avaliaram se o instrumento era adequado para a população em questão, seguindo as recomendações feitas por Hambleton (2005). Assim, a escala foi aplicada em uma amostra de conveniência de 456 membros, pertencentes a 70 grupos de trabalhos diferentes, em que cada grupo de trabalho tinha nove representantes, em média. Os participantes pertenciam a 26 organizações distintas, de setores variados (indústria, serviços e comércio) e localizadas no Centro e Centro-Norte de Portugal. A escala foi, então, ou aplicada por líderes nas organizações, previamente instruídos pelos pesquisadores, ou por meio de formulário eletrônico, através de um link disponibilizado aos participantes. Os resultados foram positivos no que diz respeito à adaptação do instrumento, que demonstrou propriedades psicométricas adequadas em relação à validade, à confiabilidade e à versão original, mostrando-se efetivo para a medição do constructo de liderança transformacional.

Um último estudo em que buscou-se analisar instrumentos de medida quanto a liderança foi o realizado por Neves e Coimbra (2019) em que foram analisadas a validade de instrumentos que mediam três diferentes constructos de estilo de liderança, aplicando-as ao contexto educativo. Os tais constructos referiam-se a liderança ética; liderança moral e liderança transformacional. Foram utilizadas, para cada constructo, um questionário específico, a saber: Ethical Leadership Questionnaire - ELQ (Neves, Jordão, Cunha, Vieira, \& Coimbra, 2016); Transformational Leadership Questionnaire - TLQ (Bass \& Avolio, 2003); Moral Leadership Questionnaire - MLQ (Mamede, Ribeiro, Gomes \& Rego, 2010). Os três questionários foram respondidos por 204 


\section{SOARDO; FANTON; JUNIOR}

professores de 30 grupos escolares distintos, do sistema educacional português. Foram realizadas análises estatísticas fatoriais dos dados obtidos e os autores constaram que as três escalas são válidas para medição de tais constructos no que tange ao público da educação de Portugal, uma vez que foram apresentados níveis de confiabilidade entre aceitável e excelente. $\mathrm{O}$ estudo contribui para futuras pesquisas diante da averiguação de adequação psicométrica dos instrumentos em questão.

\section{c) Perfil de liderança}

Carvalho Neto et al. (2012) compararam características do líder transformacional com tipos psicológicos de gestores brasileiros, a partir da disponibilização de questionários do Myers-Briggs Type Indicator (MBTI), que estabelece o tipo psicológico, a partir de quatro preferências (motivação, observação, decisão e modo de vida), designadas por letras, após a resposta fornecida por executivos de grandes empresas que operam no Brasil a testes online e impressos. Ao todo, 965 questionários foram respondidos e, dentre esses, as características que apareceram com maior frequência entre os executivos foram a facilidade para liderar e assumir o comando rapidamente. A objetividade - que pode estar relacionada a eficiência, marca de líderes transformacionais, de acordo com a literatura - também se destacou. Outro dado em consonância com a teoria transformacional é a predominância de líderes transformacionais nos cargos mais altos das organizações, principalmente aquelas que buscam líderes aptos a conduzirem mudanças. Por outro lado, é interessante indicar que o perfil que mais obteve pontuação, o ESTJ, apesar das características que vão ao encontro do líder transformacional, pode não enxergar necessidade de mudança, característica que contrasta com o perfil do líder transformacional. Outra característica de líderes brasileiros apresentada neste estudo, e que destoa do caráter do líder transformacional, diz respeito à atenção às necessidades do seu grupo, aspecto que se distancia principalmente do segundo e do terceiro tipos mais encontrados entre os participantes, a saber: o ENTJ e o ISTJ, respectivamente. Assim, apesar de algumas potencialidades de concordância entre a personalidade de líderes brasileiros e características esperadas em líderes transformacionais, de modo geral, o Brasil ainda caminha distante de um perfil gestor transformacional. 


\section{d) Estilos de liderança e variáveis relacionadas}

Alguns estudos procuram identificar variáveis que se relacionam com estilos de liderança, bem como caracterizar a natureza dessa relação, como o de Rozo-Mogollón e Abaunza-González (2010), que buscaram descrever as variáveis sociodemográficas e laborais de 94 docentes de enfermagem que trabalham nos Programas de Enfermagem das Universidades do Nordeste Colombiano (PEUNC), identificando os estilos de liderança que eles exercem e o tipo de relação existente entre os estilos de liderança e as variáveis sociodemográficas e laborais. Para tanto, os participantes responderam um questionário sobre variáveis sociodemográficas e profissionais e o MLQ-5X. Os resultados apontam que o tipo de liderança exercido pelos docentes de enfermagem que trabalham nas PEUNC é o transformacional. O gênero não permitiu uma medida objetiva como variável demográfica, dada a predominância feminina na profissão. Quanto ao nível de escolaridade, os profissionais com especialização exibiram uma abordagem moderada da liderança transformacional, enquanto as respostas das outras categorias não permitiram estabelecer relação com os tipos de liderança. A experiência de ensino e a renda mensal também não apresentam relação com os tipos de liderança e, em relação ao vínculo trabalhista e tempo de instituição, respectivamente, os catedráticos apresentaram uma baixa abordagem transacional e os docentes que estão na instituição entre 2 e 5 anos manifestaram uma abordagem moderada à categoria transformacional, no entanto, a baixa frequência das duas categorias denota uma fraca relação.

Na mesma linha, Godoy e Bresó (2013) analisaram a influência da liderança transformacional na motivação intrínseca esperada em 575 funcionários, sendo 473 pertencentes a uma empresa industrial e 102 a uma empresa do setor financeiro. Os autores basearam-se no Modelo Integrado de Motivação no Local de Trabalho (ASHMot) enunciado por de Quijano e Navarro (1998), o qual estabelece um Índice de Motivação Esperada (IMEs), que, por sua vez, identifica e estima: 1) as necessidades prioritárias; 2) a instrumentalidade, ou seja, a experiência e percepção que o sujeito tem da relação entre trabalho bem feito e satisfação das necessidades por meio das recompensas conseguidas; e 3) a relação entre ambas. Para tanto, os participantes responderam aos Questionários ASH-Mot e ASH-Lid (este último baseado no Multifactor Leadership Questionnaire - MLQ), cujos resultados deram suporte empírico à relação entre liderança transformacional e IMEs. Além disso, a motivação intrínseca 


\section{SOARDO; FANTON; JUNIOR}

se apresentou como um fator mais abrangente, não sendo possível atribuir sua promoção exclusivamente à liderança transformacional.

Outro estudo acerca de variáveis relacionadas à liderança transformacional é o de Maciel e Nascimento (2013), que analisou a relação entre as gestalts de liderança transformacional e o comprometimento organizacional, a partir de um levantamento das respostas de 331 funcionários de oito organizações do setor de serviços a questões relativas à caracterização do participante (idade, sexo, instrução e tempo na empresa) e à avaliação do comportamento de seu líder, sendo utilizado, para tanto, o Transformational Leadership Behavior Inventory (TLI) (PODSAKOFF et al., 1990). Maciel e Nascimento (2013) propõem que o conhecimento sobre os efeitos da liderança transformacional pode avançar a partir do exame do construto como configurações formadas por suas dimensões e por meio da análise dessas diferentes configurações com o comprometimento nas organizações.

Ainda sobre efeitos da liderança transformacional, Ganga Contreras et al. (2016) analisaram em um Colégio do Chile, se as dimensões desse estilo de liderança apresentam efeito no compromisso e no desempenho de seus docentes, a partir das respostas ao Questionário Multifatorial de Liderança (MLQ), de Bass e Avolio (2000), adaptado ao contexto chileno, no formato Classificador A, para docentes que atuam em sala de aula, e no formato Classificador B, para docentes que atuam em cargos de direção. Como resultado, verificou-se o impacto da colaboração e do comprometimento com o ensino em comportamentos para elevar os níveis de confiança e gerar motivação, de modo que o comportamento ético gerou processos dinâmicos na consecução de objetivos e metas. Adicionalmente, os objetivos almejados pela instituição são amplamente conhecidos pelos docentes e pelo menos $85 \%$ das pessoas na organização se comprometem com eles. Notou-se, ainda, uma relação significativa com aspectos voltados para a promoção da tarefa educativa, com a conquista de confiança por meio da credibilidade, com o apoio a determinadas ações de trabalho e com a animação em propor ideias.

$\mathrm{Na}$ mesma linha, Pessoa et al. (2018) pretenderam contribuir com o esclarecimento dos efeitos da liderança transformacional na eficácia dos grupos de trabalho, tendo por base o modelo de eficácia Input-Mediator-Outcome-Input (IMOI) de Ilgen et al. (2005), o qual, segundo os autores, afirma que a liderança pode ser vista como um antecedente da eficácia (input). Para tanto, utilizaram como método de 


\section{SOARDO; FANTON; JUNIOR}

pesquisa: a) membros de 117 equipes, de setores distintos de atividades, formadas, cada uma, por, em média, nove elementos. Estes foram inquiridos a respeito da liderança transformacional, dos comportamentos de suporte e da qualidade da experiência grupal, respectivamente por meio da escala Global Transformational Leadership (GTL), elaborada por de Carless, Wearing e Mann (2000) e adaptada para a língua portuguesa por Beveren (2015); b) de uma escala, composta por cinco itens, desenvolvida por Aubé e Rousseau (2005) e adaptada para a língua portuguesa por Pessoa (2016); c) e uma escala com três itens desenvolvidos por Aubé e Rousseau (2005) e adaptada para a língua portuguesa por Albuquerque (2016). Adicionalmente, os líderes avaliaram o desempenho de suas equipes, os processos de melhoria e sua viabilidade mediante, respectivamente, duas escalas desenvolvidas por Rousseau e Aubé (2010) e uma escala desenvolvida por Aubé e Rousseau (2005), todas adaptadas para a língua portuguesa por Albuquerque (2016).

Nesse estudo de Pessoa et al. (2018), a amostra contou com 95 líderes e as respostas a pesquisa confirmaram a relação positiva entre liderança transformacional e os comportamentos de suporte das equipes de trabalho, indicando que os comportamentos de suporte se apresentaram como mediadores totais da relação entre a liderança transformacional e o desempenho da equipe, seus processos de melhoria, sua viabilidade e a qualidade da experiência grupal, influenciando positivamente as várias dimensões da eficácia das equipes de trabalho.

Ainda sobre variáveis que se relacionam com a liderança transformacional, Rodrigues e Ferreira (2015) investigaram o impacto dos estilos de liderança transacional e transformacional nos comportamentos de cidadania organizacional, consideradas, no estudo, como atos voluntários que vão além do prescrito formalmente para funções de um determinado trabalho e que contribuem para o funcionamento adequado da organização. A mensuração dessa relação foi realizada por meio da aplicação da versão portuguesa do MLQ em uma amostra de 213 trabalhadores de quatro organizações do setor alimentício e de comércio, situadas na Baixada Fluminense, no Estado do Rio de Janeiro, adquirida diretamente do Editor Mind Garden, e também da Escala de Comportamentos de Cidadania Organizacional (CCO), questionário elaborado por Porto e Tamayo (2003), composto por 41 itens. Tais itens são relativos a sugestões criativas, à proteção ao sistema organizacional, à criação de um clima favorável à organização no ambiente externo, ao autotreinamento e à cooperação com os colegas. Como resultados, 


\section{SOARDO; FANTON; JUNIOR}

os autores apontam que o estilo de liderança transacional predisse positivamente a dimensão do CCO referente à criação de clima favorável à organização no ambiente externo, enquanto o estilo de liderança transformacional predisse positivamente as dimensões dos CCO relacionadas às sugestões criativas ao sistema, à criação de clima favorável à organização no ambiente externo, o autotreinamento e à cooperação com os colegas, tendo, portanto, apresentado maior poder preditivo sobre os CCO que o estilo de liderança transacional.

García-Rubiano (2011), por sua vez, procurou identificar o estilo de liderança de líderes de duas empresas de Bogotá, segundo a percepção de seus subordinados, e avaliar sua relação com a aceitação à mudança organizacional por parte dos funcionários, a partir da visão de seus líderes. Para tanto, a autora aplicou o instrumento de medição à mudança organizacional (IMC), elaborado por García, Rubio e Bravo (2007), em nove líderes e a versão reduzida do MLQ, adaptado por Vega e Zabala (2004), em 64 liderados. Os resultados obtidos pela autora indicaram poucas associações entre a pontuação dos líderes e a de seus liderados, o que pode ser justificado pelo tamanho reduzido da amostra. No entanto, foi observada uma associação entre a efetividade, ou seja, à otimização de recursos humanos e materiais para obter os melhores resultados possíveis com o menor custo, avaliada pelo MLQ, e a comunicação, medida pelo IMC e entendida como processo bidirecional de transferência de informação, que deixaria todos à vontade para expressar abertamente suas ideias. Outro dado importante apontado pela autora é que pouco mais da metade da amostra dos líderes apresentou um nível médio-alto de liderança transformacional: a maioria apresentou um nível alto de liderança transacional e, de forma geral, os líderes apresentaram um nível médio-baixo de liderança laissez-faire ${ }^{i}$. Por um lado, a tendência dos líderes das organizações tanto à liderança transacional quanto à transformacional sugere que eles variam o estilo de liderança de acordo com o contexto. Ademais, os resultados provenientes do IMC indicam, de forma geral, um nível alto de resistência à mudança - nos níveis grupal, individual e organizacional. Com base nesses dados, García-Rubiano (2011) constatou que a comunicação é uma dimensão importante tanto nos estilos de liderança quanto nos processos de mudança organizacional.

Outra variável importante que se relaciona com os estilos de liderança é relativa às mudanças que ocorrem dentro de uma organização. Assim, Couto-de-Souza e Tomei 


\section{SOARDO; FANTON; JUNIOR}

(2008) realizaram pesquisa para investigar o efeito das características de liderança de um gestor de uma organização familiar brasileira da área da saúde. Para tanto, as autoras se basearam nos estudos de Barbuto (2005), que fornecia características típicas dos estilos de liderança transacional e transformacional, e de Lima e Bressan (2003), sobre os tipos de mudanças que ocorrem dentro de uma organização e suas implicações. A partir dos referenciais teóricos supracitados, constatou-se que a organização passava por mudanças muito significativas, envolvendo ruptura de padrões e redirecionamento de funções. Tal mudança requer, segundo a literatura, um modelo de liderança transformacional, vista como mais efetiva no desenvolvimento de uma consciência nos liderados quanto aos objetivos da organização e de sua missão, visão e valores. No entanto, a atuação do gestor maior da organização participante era mais centrada no estilo de liderança transacional, com padrões mais rigidamente estabelecidos e indicada apenas para mudanças de caráter incremental, que não modifica as bases. As implicações disto foram negativas para a organização, a qual, até o momento da finalização do estudo de Couto-de-Souza e Tomei (2008), ainda não havia sido capaz de generalizar seus objetivos para a empresa como um todo, tampouco atingi-los, havendo ainda uma confusão dos novos papéis estabelecidos para às novas funções. Isso se deu em grande parte, de acordo com as pesquisadoras, pelo fato de o gestor em questão mostrar-se centralizador, com forte cobrança por resultados, dando frequentes feedbacks negativos e pouca atenção às dificuldades e aos questionamentos dos funcionários. Esse estilo de liderança mais centralizador, para as autoras do estudo, estimula a manutenção do status quo e dificulta a mudança e o crescimento da empresa.

Durán Gamba e Castañeda Zapata (2015), no que tange às variáveis relacionadas, objetivaram investigar, tanto a partir da perspectiva dos líderes como da dos liderados, a relação entre o estilo de liderança transformacional e transacional dos primeiros com o compartilhamento de conhecimentos por parte dos últimos e, com base nos resultados, buscaram elaborar um modelo preditivo da conduta dos liderados de compartilhar conhecimento em função dos níveis de liderança transformacional e transacional dos líderes. Para tanto, 150 funcionários (14 de cargos de liderança e 136 subordinados) de duas organizações colombianas, responderam ao MLQ, de Bass e Avolio (2000), para avaliar o estilo de liderança, e a escala de Variáveis Psicossociais e Condições Organizacionais da Conduta de Compartilhar Conhecimento, desenvolvida e validada para a população colombiana por Castañeda (2010), para avaliar o 


\section{SOARDO; FANTON; JUNIOR}

compartilhamento de conhecimentos. A relação entre liderança transformacional e o compartilhamento de conhecimentos, no entanto, só encontrou respaldo estatístico na percepção dos liderados. Adicionalmente, a autodescrição resultou em pontuações altas em liderança transformacional e transacional para $29 \%$ dos líderes, enquanto, a partir da perspectiva dos liderados, esse percentual aumentou para $40 \%$.

Outro estudo que se preocupou com a relação da liderança transformacional com outras variáveis foi o de Olvera et al. (2017), que analisou o papel mediador da confiança na equipe de trabalho - ou confiança horizontal - na relação entre liderança transformacional e o desempenho da equipe no contexto de quatro centros de cuidados com a saúde, sugerido pelo modelo Healthy and Resilient Organizations Model (HERO) de Salanova et al. (2012), adotado por empresas que realizam esforços sistemáticos, planejados e proativos para melhorar os processos e os resultados, tanto dos empregados quanto da organização. Para tanto, compararam a percepção de uma equipe composta por 388 trabalhadores, oriundos de 54 grupos de trabalho, quanto à aspectos da liderança transformacional com o desempenho da equipe, percebido pelos 54 supervisores (um de cada grupo), considerando o papel mediador da confiança horizontal também a partir da percepção da equipe de trabalho. Assim, para medir o nível de liderança transformacional, utilizaram o Questionário de Rafferty e Griffin (2004), baseado no MLQ (BASS, 1985; BASS \& AVOLIO, 1990) e, para quantificar a confiança horizontal empregaram o questionário de McAllister (1995), ambos na versão hispânica, adaptada por Salanovana et al. (2012). A performance da equipe, por sua vez, foi avaliada segundo seis itens correspondentes à adaptação da escala de performance de Goodman e Svyantek (1999), de autoria de Salanova et al. (2012). Os resultados corroboraram com o modelo HERO, indicando a confiança horizontal como forte mediador da relação entre a liderança transformacional o desempenho da equipe.

Hermosilla et al. (2016) também se preocuparam com variáveis mediadoras que se relacionam com a liderança transformacional, ao investigarem, em quatro empresas do norte da Espanha, se a liderança transformacional se associava mais fortemente, em relação a outros tipos de liderança, à percepção dos subordinados no que tange à: satisfação com o líder, efetividade do líder e sua motivação com o trabalho. Os autores também avaliaram a existência de diferenças de gênero nos estilos de liderança. Para tanto, 47 gerentes e 107 subordinados - sendo 38\% da amostra composta por mulheres - foram submetidos à versão espanhola do MLQ, proposto por Avolio e Bass (2004), 
com o intuito de avaliar a percepção dos sujeitos em relação ao comportamento de liderança e seus respectivos resultados, os quais apontaram que ambos, subordinados e gerentes, percebem a liderança transformacional como produtora de maior satisfação com o líder e maior motivação no trabalho em comparação com a liderança transacional. No entanto, no que tange à efetividade, somente os subordinados percebem-na mais atrelada à liderança transformacional do que à transacional - os gerentes, ao contrário, perceberam a liderança transacional mais fortemente associada à efetividade do que a liderança transformacional. Essa percepção, por parte dos gestores, sugere uma separação conceitual em termos de obtenção de resultados estruturais (eficiência) e a obtenção de um bom ambiente de trabalho (satisfação e motivação), o que pode estar arraigado à cultura organizacional. Quanto à diferença entre os gêneros, o estudo não encontrou diferenças entre eles nos estilos de liderança; no entanto, a baixa representatividade de amostras de algumas das empresas da pesquisa, o fato delas não serem perfeitamente compatíveis e os reduzidos coeficientes alfa para algumas medidas, provavelmente colocaram-se como algumas limitações da pesquisa (HERMOSILLA et al., 2016).

Pérez Santiago e Camps del Valle (2011) também consideraram a variável de gênero em seu estudo, cujos objetivos eram: identificar o estilo de liderança majoritariamente atribuído a um grupo de supervisores em Porto Rico; determinar a existência de diferenças estatísticas significativas entre os estilos de liderança transformacional, transacional e laissez-faire, considerando a variável gênero; e examinar se outras variáveis demográficas atuavam com o gênero na atribuição que os supervisores fazem de um estilo de liderança particular. Para este fim, 200 supervisores de várias organizações dos setores de serviço e de manufatura (sendo 44\% mulheres) responderam o Questionário de Estilos de Liderança (CELID), Forma A, que consiste em uma operacionalização da teoria de liderança de Bass (1985), desenvolvido por Solano et al. (2007). Os participantes também responderam alguns dados demográficos e perguntas destinadas a saber se o participante teve treinamento sobre liderança e, em caso afirmativo, em que quantidade. Como resultado, foram atribuídos mais pontos ao estilo de liderança transformacional, seguido pelo transacional e, por último, pelo laissez-faire. Para os supervisores, existe uma relação positiva e significativa entre a dimensão transacional de recompensa contingente e as dimensões transformacionais de estimulação intelectual, consideração individual e pontuação geral de liderança 


\section{SOARDO; FANTON; JUNIOR}

transformacional, o que indicou que o líder visa esclarecer os níveis de desempenho esperados, prestar atenção às necessidades individuais de seus seguidores e proporcionar melhorias para os seguidores na forma de solucionar problemas. Quanto ao gênero, às mulheres se atribuíram, em comparação aos homens, maiores níveis de liderança transformacional e níveis significativamente maiores de liderança transacional. As respostas ao questionário, dada sua natureza autoavaliativa, podem tanto ser uma representação do que de fato ocorre quanto a escolha de fatores mais desejáveis para um líder efetivo, o que, por sua vez, forneceria um ponto de partida para pensar o que representa o estilo de liderança ideal, a partir da perspectiva desse grupo. No entanto, em termos desse estudo, isso pode ser considerado uma limitação.

Abelha, Carneiro e Cavazotte (2018) também versaram sobre algumas variáveis demográficas ao pesquisar a influência do gênero dos subordinados, de sua área de formação profissional e da natureza da organização (pública ou privada) na relação entre a liderança transformacional e a satisfação no trabalho, utilizando os estados de afetividade dos respondentes como variável de controle. Para tanto, foi realizada uma pesquisa quantitativa, com 166 funcionários de diferentes empresas, áreas de formação profissional e gênero. Os dados foram levantados por meio de cinco questionários eletrônicos, a saber: questionário sobre liderança transformacional, adaptado do MLQ de Avolio e Bass (2004), validado para português por Fonseca e Porto (2013); questionário de satisfação no trabalho, adaptado do questionário JDI (Job Descriptive Index) de Smith, Kendall e Hulin (1969), validado para português por Jesuíno, Soczka e Matoso (1983); questionário sobre o estado de afetividade do respondente, adaptado do questionário POMS (Profile of Mood States) de McNair, Lorr e Droppleman (1992) e validado por Viana, Almeida e Santos (2001); e questionário sobre dados demográficos levantando as características pessoais dos respondentes. Os dados levantados foram analisados utilizando regressão sequencial e os resultados obtidos indicam que a relação entre a liderança transformacional e a satisfação no trabalho é mais realçada para subordinados do sexo feminino, embora não se altere com base na sua área de formação profissional ou na natureza da organização (pública/privada).

Outra variável investigada em associação com a liderança transformacional foi a saúde e o bem-estar do trabalhador, bem como a mediação da confiança no líder nessa relação, em países em desenvolvimento, nos quais os valores culturais se distinguem dos de países em que, tradicionalmente, se têm pesquisado o modelo de liderança 


\section{SOARDO; FANTON; JUNIOR}

transformacional. Para tanto, Perilla-Toro e Gómez-Ortiz (2017) realizaram estudo quantitativo com 597 empregados, de empresas do setor público e privado, da Colômbia e do México. O estudo objetivou ampliar o panorama de indicadores de bem-estar ocupacional dos subordinados com os quais a liderança transformacional pode se relacionar, incluindo medidas de mal-estar e de bem-estar psicológico, isso porque muitos estudos dizem avaliar o bem-estar psicológico, quando, na verdade, estão avaliando a ausência de mal-estar como sinônimo de bem-estar, fato esse que, para os autores, é um erro conceitual. Para não incorrer no mesmo erro, os autores optaram por descrever os conceitos de liderança transformacional, de bem-estar e de saúde mental e de confiança como mediador.

Para coleta de dados, foi aplicado um questionário sociodemográfico; a versão espanhola reduzida do MLQ, validada por Alonso, Saboya e Guirado (2010), para avaliar a liderança transformacional; a Escala de Confiança Interpessoal no Trabalho, desenvolvida por Cook e Wall (1980), para avaliar a confiança no líder; a versão espanhola de 12 itens da escala unidimensional do Questionário Geral de Saúde, adaptada por Álvaro (1992), para avaliar os sintomas de mal-estar; a adaptação espanhola da versão reduzida da Escala de Ryff (1989), proposta por van Dierendonck (2004), para avaliar o bem-estar psicológico; a adaptação da escala desenvolvida por Shouksmith (1990), realizada por Paris (2008); a adaptação, em espanhol, realizada por Bravo et al. (1993) do Questionário de Satisfação de Minnesota, para avaliar a satisfação com o trabalho; a versão em espanhol feita por Pepe et al. (2010) da Escala de Avalone, para avaliar auto-eficácia no trabalho; e, por fim, a versão espanhola validada por Sandín et al. (1999) do Questionário de Afeto Positivo e Negativo (PANAS), para avaliar afetividade. Como resultado, notaram a existência de relação negativa entre liderança transformacional e mal-estar psicológico e associação entre liderança transformacional e satisfação com o trabalho, mas não com o bem-estar psicológico. O que se mostrou decisivo para o bem-estar psicológico foram aspectos pessoais, como afetividade, grau de escolaridade e auto-eficácia. Por outro lado, o grau de liderança transformacional só foi percebido às vezes, de modo que pode faltar esforço extra e motivação transcendente por parte do líder, características de um elevado nível de liderança transformacional e que, provavelmente, se associariam mais com o bem-estar psicológico (PERILLA-TORO; GÓMEZ-ORTIZ, 2017). Ainda foi possível identificar uma mediação total - e não parcial, como se hipotetizava - da 


\section{SOARDO; FANTON; JUNIOR}

confiança no líder na relação entre a liderança transformacional e a satisfação com o trabalho e na relação entre a liderança transformacional e os sintomas de desconforto. A autoeficácia, por sua vez, não apresentou nenhuma relação com a liderança transformacional, configurando-se somente como um mecanismo implicado na relação. Levando em conta que a autoeficácia foi medida de maneira específica, os autores levantaram a suposição de que a liderança transformacional tem uma relação positiva somente com a autoeficácia em geral, não com a autoeficácia no trabalho, que, no entanto, demonstrou uma forte correlação positiva com variáveis pessoais, como idade e bem-estar psicológico.

Outra variável pontuada na relação com a liderança transformacional foi a coesão e a identificação grupal, investigada por García-Guiu et al. (2016), que buscaram relacionar a potência de grupo de pequenas unidades militares, no que tange aos efeitos diretos e indiretos da liderança transformacional em líderes de esquadrões na potência grupal. A amostra composta por 243 membros de 51 esquadrões de unidades operacionais do exército espanhol, representados, por sua vez, por seis respondentes de cada esquadrão foi submetida a quatro questionários para cada categoria de análise: $M L Q$, de Alonso, Saboya e Guirado (2010); as escalas de potência e identificação grupal desenvolvidas por Shamir, Zakay, Brainin e Popper (2000), traduzidas e adaptadas para tal estudo, com base em uma versão anterior de Muñiz, Elosua e Hambleton (2013); a subescala Group Integration Task do Group Environment Questionnaire (GEQ) da tradução de Iturbide, Elosua e Yanes (2010). Como resultado, é cabível destacar o efeito mediador que a identidade e a coesão do grupo proporcionaram à liderança transformacional, permitindo sua expressão de forma mais significativa. Os efeitos referentes à potência grupal serão discutidos na seção da categoria "estilos de liderança e áreas afins".

Um último estudo dentro desta categoria de análise é o de Strapasson e Medeiros (2009), que tinha por objetivo identificar se a cultura organizacional de um hospital privado, de médio porte, do interior do Rio Grande do Sul, favorecia a prática da liderança transformacional e investigar se a organização estimulava o desenvolvimento de lideranças. Para tanto, 11 enfermeiras-líderes de diferentes setores do hospital analisado responderam a uma entrevista semiestruturada; nove delas perceberam a instituição hospitalar como estimuladora do exercício da liderança e, embora ainda não estivessem totalmente presentes no seu cotidiano, alguns dos pressupostos da liderança 
transformacional foram identificados como importantes.

\section{e) Estilos de liderança e educação}

A relação entre liderança e contexto educacional aparecem em Vázquez-Alatorre (2013), que considerou a liderança transformacional no contexto de estruturação de ambientes de ensino que atendiam as demandas do século XXI e refletiu sobre questões que precisavam ser respondidas no padrão de interação entre as operações realizadas por líderes transformacionais, a cultura organizacional em instituições educativas e outros fatores contextuais e situacionais. Para tanto, o autor explicou o conceito de liderança transformacional, partindo da construção do conceito e passando por seus elementos distintivos e suas implicações gerais para, então, comparar aspectos da liderança transformacional e da liderança transacional, elencando os tipos de líderes transformacionais e apontando a relação entre o líder transformacional e o processo de mudança organizacional. A análise contou também com considerações sobre como a cultura organizacional influencia o processo de liderança transformacional e como o processo afeta a cultura.

No que diz respeito ao contexto escolar propriamente dito, há a pesquisa realizada em um colégio chileno por Ganga Contreras et al. (2016). Um de seus objetivos era, basicamente, identificar o perfil dos professores em sala de aula e a incidência de práticas características de uma liderança transformacional por parte da gestão docente em uma escola. Para a obtenção desses dados, foi utilizado o MLQ, de Bass e Avolio (2000), adaptado ao contexto chileno em dois formatos: um para professores em sala de aula e outro para professores que atuam em cargos de direção. Verificou-se, tanto nos professores que atuam em cargos de direção quanto nos que atuam em sala de aula, a incidência positiva de características relativas à liderança transformacional, sendo as que mais se destacaram: o compromisso, a comunicação (direta e indireta), o papel formal (não necessariamente discricionário) e a motivação. Também observou-se o impacto da colaboração e do comprometimento com o ensino em comportamentos para elevar os níveis de confiança e gerar motivação. A estimulação intelectual e o apoio individualizado, por seu turno, apareceram como aspectos de menor frequência, tanto em docentes que atuam em sala de aula quanto em docentes que atuam na direção, possivelmente em razão do impacto de um ambiente macro estável. 


\section{f) Estilos de liderança e área da saúde}

Dentre os artigos pesquisados e que atenderam aos critérios de inclusão, foram encontrados cinco artigos que aplicaram o conceito de liderança transformacional no âmbito da saúde, sendo dois os assuntos principais em relação aos objetivos dos estudos destacados são: efeitos e relevância da vigência de uma liderança transformacional dentro de uma organização de saúde e identificação do estilo de liderança que se faz presente nas organizações de saúde. A revisão bibliográfica de Espinoza Quiroz e Peduzzi (2013) objetivava aprofundar o entendimento sobre a organização dos profissionais de saúde e compreender a funcionalidade do líder transformacional na conquista dos objetivos desses trabalhadores, considerando um clima que promova a participação e apoie a inovação, fornecendo serviços de qualidade aos usuários e à organização. A pesquisa foi realizada em oito bases de dados, incluindo todos os artigos entre 1998 e 2013, e partindo de descritores relacionados à liderança, liderança transformacional, comportamento cooperativo, trabalho em equipe, clima laboral, etc. Os resultados apontaram a inexistência de artigos que relacionasse a liderança transformacional e o clima em equipes de saúde. Contudo, a prática de apoio à inovação tem sido apontada como uma dimensão do clima da organização e como característica de uma liderança transformacional, mediando a excelência no cuidado.

Ainda no que diz respeito à relevância e aos efeitos de uma liderança transformacional, pode-se relatar o estudo de caso, de caráter qualitativo, de Weymer e Moreira (2017), que trata do papel do líder em situações de mudanças organizacionais, no que tange a relação deste com a equipe de trabalho e como esta se comporta frente às transformações, a partir dessa forma de liderança. Participaram da pesquisa gestores de quatro hospitais todos integrantes de uma mesma organização, de modo que três níveis dentro da hierarquia organizacional - gerência, coordenação e diretoria - responderam a um roteiro de entrevista semiestruturado, cujas respostas foram transcritas e submetidas a análise de discurso, segundo orientações de Bardin (2011). Posteriormente, foi realizado o cruzamento das informações das entrevistas e de documentos organizacionais, analisados em termos do planejamento estratégico da organização, de seus valores e missão. A partir desse cruzamento, os autores redigiram um questionário relativo ao olhar do liderado sobre a liderança organizacional que, por sua vez, foi aplicado em $80 \%$ dos componentes das instâncias das gerências. As informações 


\section{SOARDO; FANTON; JUNIOR}

obtidas por esses diferentes procedimentos metodológicos permitiram constatar que nessa organização, mesmo diante de problemáticas organizacionais, os líderes gozavam de uma boa impressão por parte de seus liderados, ainda que não estivessem sendo verdadeiramente representativos de um líder transformacional, uma vez que, diante das informações coletadas, não pareceram capazes de transmitir aos seus liderados os valores da transformação - o que os autores destacaram como importante característica desta forma de liderança. Vale destacar que os autores do artigo entendem a limitação de sua pesquisa por se tratar de um recorte situacional de uma organização em específico, mas que os dados obtidos foram importantes para pontuar possíveis aspectos de intervenções e melhorias organizacionais, sem a pretensão de estender tais constatações para um campo maior de outras organizações de trabalho.

Dentro dessa categoria, observa-se também o artigo de Pucheu (2010), que trata da influência da prática de liderança, com enfoque na transformacional, na saúde dos trabalhadores, especialmente no que se refere ao burnout $t^{i i}$. Para tanto, foram realizadas reuniões com os executivos dos hospitais participantes, seguidas por ntrevistas individuais com supervisoras e reuniões breves com as enfermeiras dos serviços para explicar os objetivos e procedimentos de investigação. Em seguida, foram entregues o MLQ e o Questionário de Burnout de Maslach (MBI) a cada uma das 259 enfermeiras, sendo 74 de um hospital público e 185 de um hospital privado. Por fim, os resultados foram obtidos a partir de quatro oficinas, nas quais a participação foi voluntária e abriu espaço para as participantes opinarem sobre os resultados obtidos nos questionários supracitados. Duas das oficinas contaram com a participação de 32 enfermeiras supervisoras e duas com a de 43 enfermeiras subalternas. Assim, os dados sugerem que a frequência com que as supervisoras realizam ações associadas à liderança transformacional afeta o nível de burnout das subalternas, no entanto as oficinas indicaram que a influência do líder só explica uma pequena parte da variância no grau de burnout. Quanto à influência das supervisoras sobre as subordinadas, constatou-se que variáveis atreladas à estrutura do hospital e a percepção geral sobre a relação construída entre supervisoras e subordinadas mediam essa relação. O estudo revelou, ainda, que a capacidade das supervisoras de influenciar as lideradas deve considerar o desenvolvimento de ações que facilite a coesão entre pares, de modo a favorecer um espírito de cooperação, fortalecendo sua disciplina e coordenação, o que demonstra características de uma liderança transformacional, no sentido de promover o seguimento 


\section{SOARDO; FANTON; JUNIOR}

de objetivos grupais, por exemplo.

Com o objetivo de verificar se os pressupostos a respeito da liderança transformacional apareciam nas práticas dos enfermeiros ocupantes de cargos de gestão de um hospital de médio porte do interior do estado do Rio Grande do Sul, Strapasson e Medeiros (2009) realizaram, por meio de entrevista semiestruturada, com questões sobre "as habilidades que o enfermeiro considera essencial para o exercício da liderança", como está sendo o exercício dessas habilidades no cotidiano dos enfermeiros e a participação da organização no desenvolvimento da liderança (STRAPASSON; MEDEIROS, 2009). No que diz respeito ao significado de liderança, os resultados demonstraram o desconhecimento desse tema, a presença de crenças da liderança como uma habilidade inata a ser desenvolvida, bem como questões próximas às características pressupostas de uma liderança transformacional, como $\mathrm{o}$ compromisso, o guia a um objetivo de grupo e habilidades comunicativas. Ademais, quando questionados sobre as habilidades essenciais para o exercício de liderança, alguns participantes elencaram o conhecimento técnico e científico de enfermagem como algo importante. Alguns outros se aproximaram das habilidades definidas na literatura de flexibilidade, a motivação, visão e a comunicação.

Por último, encontra-se o estudo realizado por Ferreira et al. (2018) em que buscaram identificar o estilo de liderança exercido por enfermeiros em um hospital universitário. O método de investigação utilizado pelos autores contou com dois momentos: questionário e entrevista semiestruturada. O método quantitativo obteve 152 respondentes dos 234 convidados à participação. O questionário continha em seus 22 itens comportamentos quanto ao exercício de liderança, e 14 destes estavam relacionados ao estilo de liderança transformacional e oito ao estilo de liderança transacional. Os itens deveriam ser respondidos a partir de uma escala likert de frequência, com variação de 0 (zero) a 10 (dez), em que 0 (zero) correspondia a nunca e 10 (dez) a sempre. Os dados obtidos foram analisados com auxílio de software estatístico (SPSS 21.0) e as respostas a cada item foram categorizadas em "inexistente ou pouca prática", prática mediana" e "prática frequente". Então, para a etapa do método qualitativo, Ferreira et al. (2018) realizaram a entrevista com 25 dos participantes da primeira fase (quantitativa), os quais foram sorteados aleatoriamente para participação. As entrevistas duraram em média 30 minutos e tiveram como pergunta norteadora “como você costuma exercer sua liderança?". Os dados obtidos 


\section{SOARDO; FANTON; JUNIOR}

foram analisados por meio da técnica de análise de conteúdo de Minayo (2014), com auxílio do software Nvivo 11.

Os resultados obtidos na primeira fase por Ferreira et al. (2018) foram que as variáveis do estilo de liderança transformacional expressam uma "prática frequente" superior à 50,0\% dos participantes, em 13 dos 14 comportamentos comuns referentes a esta expressão de liderança, explicitando sua primazia em meio aos participantes da pesquisa. Das oito variáveis referentes ao estilo de liderança transacional, cinco obtiveram como resultado uma "prática mediana" superior a 50\% dos participantes, e nenhuma apresentou "prática inexistente ou pouca prática" e "prática frequente" superior a $50 \%$ que pudesse ser relevante para constatações referentes a esta expressão de liderança na amostra. A segunda fase (qualitativa) de entrevista permitiu evidenciar categoria de análise referente a facilitadores ou impeditivos da expressão do estilo de liderança transformacional, independentemente do cargo exercido. Aqui ficou evidente que a organização do trabalho existente na instituição dos participantes não favorecia e tampouco apoiava esse perfil de líder, além de dificultar a identificação de líderes para além daqueles que exerciam gestão. Foram apontadas razões como a verticalização da gestão quanto à tomada de decisões e a falta de incentivo à formação de líderes como fatores predisponentes a essa realidade apresentada na pesquisa.

\section{g) Estilos de liderança e áreas afins}

Entre os artigos selecionados para essa revisão, alguns se desenvolveram em áreas distintas das categorias elencadas, porém específicas demais para justificarem categorias próprias, de modo que, esta categoria foi elaborada para contemplar tais estudos e suas implicações. Álvarez et al. (2016), por exemplo, realizaram uma revisão bibliográfica, na qual buscaram levantar a literatura internacional que tratasse da liderança transformacional dentro de contextos de esporte e atividades físicas. Foram coletados artigos com informações até abril de 2015, a partir dos quais foi feita uma análise bibliométrica e de conteúdo, selecionando-se, por fim, 28 artigos a serem analisados. Os resultados indicam que líderes transformacionais vêm servindo de modelo para os atletas e implantando significados e desafios nas atividades diárias, o que ilustra a motivação inspiradora, característica de líderes transformacionais. Além dessas questões, os autores relatam que o efeito ocasionado nos atletas pelos líderes transformacionais varia conforme a personalidade dos esportistas, uma vez que o apoio 
e às expectativas do líder podem ser percebidos como um fator premente para atletas que têm personalidade com traços altamente narcísicos (ÁLVAREZ et al., 2016).

Para mais, Garcés-Bedoya (2016) realizou reflexão a respeito da liderança transformacional dentro de comunidades, no que se refere às artes, à cultura e à educação. Tal material refere-se, em grande parte, aos aspectos individuais e introspectivos da liderança e defende a ideia de um poder transformador das artes dentro de uma comunidade, no sentido desenvolvimentista que se manifestará diante de condições para isso, como estratégias criativas e funcionais que tornem o indivíduo participante dessa atividade artística ator principal de sua transformação e assim, possa modificar o ambiente. A autora afirma que a arte é capaz de formar indivíduos, que poderiam servir de líderes transformacionais à sociedade. No entanto, ressalta que esta deve ser uma construção conjunta entre diversas áreas do conhecimento, como a pedagogia social. Machado (2011), também por meio de uma revisão bibliográfica, teve por objetivo sustentar o raciocínio que aponta o estilo de liderança transformacional como um dos mais adequados para as Instituições Particulares de Solidariedade Social (IPSS) lidarem com os desafios a que estão atualmente sujeitas, no que tange a gestão dos recursos humanos. O estudo, que não traz maiores especificidades de metodologia e critérios de inclusão, divide-se em caracterização das IPSS; em forças e ameaças na gestão do RH da IPSS; em conceito de liderança transformacional e no porquê da liderança transformacional na gestão de RH (GRH) das IPSS. Assim, como as IPSS são organizações que enfrentam constantes e fortes mudanças, é necessário que tenham a sua frente um líder hábil a conduzir seus liderados durante tais transformações, de forma a deixar claros os objetivos e promover formas de trabalho motivadoras para eles. Ao pensar neste cenário, pode-se entender o clamor dentro das IPSS por lideranças transformacionais, às quais serão capazes de funcionar como inspirações para a persistência no alcance dos interesses coletivos e organizacionais, muitas vezes em detrimentos dos individuais, o que é vital dentro de qualquer organização, especialmente dentro destas inseridas em grandes mudanças (MACHADO, 2011).

Além do mais, retoma-se a questão da potência grupal, apresentada por GarcíaGuiu et al. (2016) como a crença dos membros do grupo quanto à eficácia coletiva. Os autores apresentam essa construção como essencial para o grupo no que tange ao enfrentamento de adversidades, e também para compreensão dos processos grupais e de como estes se relacionam com o desempenho grupal. Nesse sentido, apontam para o 


\section{SOARDO; FANTON; JUNIOR}

papel da liderança transformacional no cenário de desenvolvimento de uma potência grupal, o que se evidenciou nos resultados dos questionários.

Por fim, tem-se o estudo realizado por Rojero-Jiménez, Gómez-Romero e Quintero-Robles (2019) que analisaram a influência da liderança transformacional dos gestores nos seus liderados das micros, pequenas e médias (Mipeme) mexicanas, da cidade de Durango. Tratou-se de um estudo transversal. A metodologia utilizada fora o questionário original de Bass e Avolio (2000) desenvolvido para medição da liderança transformacional e o questionário de Antelo, Prilipko e Sheridan-Pereira (2010), o qual consiste em 12 características levantadas pelos autores que seriam referentes aos liderados quanto aos seus atributos enquanto membros do grupo, cruzando-se as informações. Os instrumentos foram respondidos pelos gestores/diretores e pelos funcionários de 360 empresas categorizadas como do ramo Mipeme. Do grupo de funcionários de cada empresa, foram selecionados 360 funcionários do setor operacional para que se evitasse o viés reducionista apenas dos gestores a respeito do desempenho de seus funcionários. Além disso, foram aplicadas um questionário sociodemográfico aos participantes a fim de identificar, especialmente, o nível de escolaridade dos participantes.

Rojero-Jiménez et al. (2019) obtiveram resultados que demonstraram que os 7 fatores elencados no teste de Bass e Avolio (2000) (influência idealizada, motivação inspiradora, estimulação intelectual, contraprestação individualizada, recompensas contingentes, administração por exceção e laissez faire) influenciam nos 12 atributos dos seguidores (confiabilidade como membro do grupo; facilidade para apoiar os outros; relações grupais; contribuição ao grupo; flexibilidade; compreensão conceitual; comunicação efetiva; relações interpessoais; aprendizagem e aceitação de mudança; inteligência emocional; motivação para alcance de objetivos; tolerância). Essa influência se dá no sentido de as habilidades do líder transformacional proporcionar o desenvolvimento das competências dos liderados, o que demonstra ainda mais a responsabilidade do líder diante do desempenho de sua equipe.

\section{CONSIDERAÇÕES FINAIS}

Diante das informações obtidas nesta revisão, nota-se a necessidade de maiores estudos e esclarecimentos acerca da liderança transformacional, suas implicações e sua 


\section{SOARDO; FANTON; JUNIOR}

expressão no âmbito das organizações e das diferentes comunidades. Tendo este cenário em vista, assim como apontado por Rozo-Mogollón e Abaunza-González (2010), é evidente que há a necessidade de continuidade de seus estudos da liderança transformacional para aprimorar a liderança de profissionais do magistério e, consequentemente, melhorar a qualidade de ensino. Adicionalmente, faz-se necessário a inclusão de uma cátedra de liderança nos programas de enfermagem, a fim de tornar o profissional formado capaz de liderar diferentes processos no campo da saúde. Endossando este argumento, Strapasson e Medeiros (2009) sugerem uma transversalidade do tema "Liderança e Liderança Transformacional" nos currículos dos cursos de enfermagem, tendo em vista a dificuldade dos enfermeiros-chefes tanto na definição de liderança, quanto em levantar características pertinentes ao sujeito-líder, observada por tais autores.

Quanto a pesquisas futuras, em concordância com Ganga Contreras et al. (2016) defendemos que as variáveis associadas a liderança transformacional sejam mais bem descritas e que, partindo de sua pesquisa, se investiguem uma amostra maior de docentes e um grupo diverso de estabelecimentos. Também apoiando a recomendação dos autores quanto à elaboração de um modelo para diagnosticar o estilo de liderança em unidades educativas, de modo a facilitar a replicação de estudos em outras entidades da mesma modalidade. Sugere-se, ainda, que os próximos estudos não se centrem somente em objetivos individuais, mas na performance da equipe de trabalho e em investigações multiníveis dos efeitos da liderança transformacional, uma vez que a maioria dos estudos se concentrou ou somente em resultados individuais ou somente em resultados coletivos. Sugere-se que futuramente sejam desenvolvidos estudos que identifiquem de forma mais explícita a influência dos fatores organizacionais (cultura organizacional, por exemplo) na expressão dos perfis de liderança. Sobre elementos que interferem na liderança, diante das análises realizadas nesta revisão, damos suporte ao proposto por Hermosilla et al. (2016), ou seja, que pesquisas futuras deem conta do tipo de influência que decorre da liderança transformacional, focando na análise de variáveis mediadoras, como, por exemplo, a persuasão.

Constata-se, mesmo diante de tantas pesquisas apresentadas, a necessidade de uma maior sistematização dos métodos de pesquisa, de forma a proporcionar maior confiabilidade aos resultados obtidos, no sentido de levar em conta as limitações dos dados comparativos entre indivíduos pertencentes a grupos diferentes de trabalho ou de 
identificar influência de um líder em sua equipe, desconsiderando a opinião da própria equipe.

Por fim, outra sugestão relevante para estudos futuros é que estes enfoquem no desenvolvimento de lideranças transformacionais, por meio da elaboração e aplicação de programas organizacionais de treinamento e desenvolvimento, nos quais os indivíduos possam ter a oportunidade de desenvolver e/ou fortalecer as competências esperadas no exercício desse estilo de liderança.

Quanto às limitações desta revisão, é possível elencar a busca somente por artigos, deixando de fora teses, monografias, trabalhos de conclusão de curso, livros e capítulos de livros. O método utilizado também foi uma forma de afunilar a pesquisa, uma vez que foram selecionados descritores somente em português e que se encontravam apenas nos títulos dos artigos, de modo que buscas em outras bases de dados, com descritores em outros idiomas e também no corpo do texto retornariam uma quantidade muito mais ampla de material e, possivelmente, levantariam maiores informações e discussões a respeito do tema.

\section{REFERÊNCIAS}

ABELHA, D. M.; CARNEIRO, P. C. D. C.; CAVAZOTTE, F. D. S. C. N. Transformational leadership and job satisfaction: assessing the influence of organizational contextual factors and individual characteristics. Revista Brasileira de Gestão de Negócios, v. 20, n. 4, p. 516-532, 2018.

ALBUQUERQUE, L. B. Team resilience and team effectiveness: Adaptation of measuring instruments. 2016. (Unpublished Master's thesis) - Faculdade de Psicologia e Ciências da Educação, Coimbra, Portugal, 2016.

ALONSO, F. M.; SABOYA, P. R.; GUIRADO, I. C. Liderazgo transformacional y liderazgo transaccional: un análisis de la estructura factorial del Multifactor Leadership Questionnaire (MLQ) en una muestra española. Psicothema, v. 22, n. 3, p. 495-501, 2010.

ÁLVAREZ, O. et al. Transformational leadership on the athletic field: An international review. Revista de Psicología del Deporte, v. 25, n. 2, p. 319-326, 2016.

ÁLVARO, J. L. Desempleo y bienestar psicológico. Barcelona: Siglo XXI de España, 1992.

ANTELO, A.; PRILIPKO, E. V.; SHERIDAN-PEREIRA, M. Assessing effective attributes of followers in a leadership process. Contemporary Issues in Education Research (CIER), v. 3, n. 9, p. 33-44, 2010.

AUBE, C.; ROUSSEAU, V. Team Goal Commitment and Team Effectiveness: The 


\section{SOARDO; FANTON; JUNIOR}

Role of Task Interdependence and Supportive Behaviors. Group Dynamics: Theory, Research, and Practice, v. 9, n. 3, p. 189, 2005.

AVOLIO, B. J.; BASS, B. M.; JUNG, D. I. Re-examining the components of transformational and transactional leadership using the Multifactor Leadership. Journal of occupational and organizational psychology, v. 72, n. 4, p. 441-462, 1999.

AVOLIO, B.; BASS, B. Multifactor Leadership Questionnaire. 3rd. ed. New York: Manual and Sampler Set. Mind Garden, 2004.

BAILEY, J.; AXELROD, R. H. Leadership lessons from Mount Rushmore: An interview with James MacGregor Burns. The Leadership Quarterly, v. 12, n. 1, p. 113$121,2001$.

BARBUTO JR, J. E. Motivation and transactional, charismatic, and transformational leadership: A test of antecedents. Journal of Leadership \& Organizational Studies, v. 11, n. 4, p. 26-40, 2005.

BARDIN, L. Análise de Conteúdo. São Paulo: Edições 70, 2011.

BASS, B. M. Leadership and performance beyond expectations. New York: Collier Macmillan, 1985.

BASS, B. M.; AVOLIO, B. J. Transformational leadership development: Manual for the multifactor leadership questionnaire. Palo Alto: Consulting Psychologists Press, 1990.

BASS, B. M.; AVOLIO, B. J. Transformational leadership and organizational culture. Public administration quarterly, v. 17, n. 1, p. 112-121, 1993.

BASS, B. M.; AVOLIO, B. J. Full range leadership development: Manual for the Multifactor Leadership Questionnaire. Palo Alto: Mind Garden, 1997.

BASS, B. M.; AVOLIO, B. J. Multifactor Leadership Questionnaire (MLQ Form 5xshort). Redwood City, CA: Mind Garden, 2000.

BASS, B. M.; AVOLIO, B. J. MLQ Multifactor Leadership Questionnaire. Redwood City, CA: Mind Garden, 2003.

BEVEREN, P. V. Liderança Transformacional e Autonomia Grupal: Adaptação de Instrumentos de Medida. 2015. Dissertação (Mestrado em Psicologia das Organizações e do Trabalho) - Faculdade de Psicologia e de Ciências da Educação, Universidade de Coimbra, Coimbra, 2015.

BEVEREN, P. V. et al. Psychometric properties of the Portuguese version of the Global Transformational Leadership (GTL) scale. Revista de Psicología del Trabajo y de las Organizaciones, v. 33, n. 2, p. 109-114, 2017.

BRAVO, M. J.; GARCÍA, J. A.; PEIRÓ, J. M.; PRIETO, F. Satisfacción con el trabajo. Los jóvenes ante el primer empleo: el significado del trabajo y su medida. Valencia: Nau Llibres, 1993.

CALAÇA, P. A.; VIZEU, F. Revisitando a perspectiva de James MacGregor Burns: qual é a ideia por trás do conceito de liderança transformacional? Cadernos EBAPE.BR, v. 13, n. 1, p. 121-135, Epub March 00, 2015.

CARLESS, S. A.; WEARING, A. J.; MANN, L. A short measure of transformational leadership. Journal of business and psychology, v. 14, n. 3, p. 389-405, 2000. 
CARVALHO NETO, A. et al. Executivos brasileiros: na contramão do perfil deificado da liderança transformacional. Revista de Ciências da Administração, v. 14, n. 32, p. 35-49, 2012.

CASTAÑEDA, D. I. Variables psicosociales y condiciones organizacionales intervinientes en la intención y conducta de compartir conocimiento. 2010 (Disertación Doctoral) - Facultad de Psicología, Universidad Autónoma de Madrid, Madrid, 2010.

COOK, J.; WALL, T. New work attitude measures of trust, organizational commitment and personal need non-fulfilment. Journal of occupational psychology, v. 53, n. 1, p. 39-52, 1980.

COUTO-DE-SOUZA, C. L.; TOMEI, P. A. Impactos de uma liderança transacional em um processo de mudança transformacional. Revista Psicologia Organizações e Trabalho, v. 8, n. 2, p. 98-120, 2008.

CRUZ-ORTIZ, V.; SALANOVA, M.; M. MARTÍNEZ, I. Liderazgo transformacional: investigación actual y retos futuros.Universidad \& Empresa, v. 15, n. 25, 13-32, 2013.

DURÁN GAMBA, M.; CASTAÑEDA ZAPATA, D. Relación entre liderazgo transformacional y transaccional con la conducta de compartir conocimiento en dos empresas de servicios. Acta Colombiana de Psicología, v. 18, n. 1, p. 135-147, 2015.

DVIR, T. et al. Impact of transformational leadership on follower development and performance: A field experiment. Academy of management journal, v. 45, n. 4, p. 735 744, 2002.

ESPINOZA QUIROZ, P.; PEDUZZI, M. Equipos de Salud Interdisciplinarios y Liderazgo Transformacional, Juntos Pueden Propiciar Mejores Resultados para Pacientes y Profesionales. Horizonte de enfermeria, v. 24, n. 1, p. 50-59, 2013.

FERNANDES, C. M.; SIQUEIRA, M. M. M.; VIEIRA, A. M. Impacto da percepção de suporte organizacional sobre o comprometimento organizacional afetivo: o papel moderador da liderança. Revista Pensamento Contemporâneo em Administração, v. 8, n. 4, p. 140-162, 2014.

FERREIRA, V. B. et al. Liderança transformacional na prática dos enfermeiros em um hospital universitário. Acta Paul Enferm., v. 31, n. 6, p. 644-50, 2018.

FONSECA, A. M.; PORTO, J. Validação fatorial de escala de atitudes frente a estilos de liderança. Avaliação Psicológica, v. 12, n. 2, 157-166, 2013.

GANGA CONTRERAS, F. et al. Liderazgo transformacional y su incidencia en la gestión docente: el caso de un colegio en el norte de chile. Interciencia, v. 41, n. 9, p. 596-604, 2016.

GARCÉS-BEDOYA, A. DEL P. Cosmovisión artística del liderazgo transformacional en pro del desarrollo comunitario. (pensamiento), (palabra). Y Obra, n. 15, p. 86-95, 2016.

GARCÍA-GUIU, C. et al. Transformational leadership and group potency in small military units: The mediating role of group identification and cohesion. Revista de Psicología del Trabajo y de las Organizaciones, v. 32, n. 3, 145-152, 2016.

GARCÍA, M.; RUBIO, P.; BRAVO, L. Relación entre factores de riesgo psicosocial y resistencia al cambio en empresa de seguridad del sector económico terciario. Revista Diversitas Perspectivas en Psicología, v. 3, n. 2, p. 301-316, 2007.

Revista Eletrônica Gestão e Serviços v.11, n. 2, pp. 3098 - 3129, Julho/Dezembro 2020. ISSN Online: 2177-7284 e-mail: regs@metodista.br 
GARCÍA-RUBIANO, M. Liderazgo transformacional y la facilitación de la aceptación al cambio organizacional. Pensamiento Psicológico, v. 9, n. 16, 41-54, 2011.

GODOY, R.; BRESÓ, E. (2013). ¿Es el liderazgo transformacional determinante en la motivación intrínseca de los seguidores? Revista de Psicología del Trabajo y de las Organizaciones, v. 29, n. 2, 59-64, 2013.

GOODMAN, S. A.; SVYANTEK, D. J. Person-organization fit and contextual performance: Do shared values matter. Journal of vocational behavior, v. 55, n. 2, 254275, 1999.

HAMBLETON, R. K.; MERENDA, P. F.; SPIELBERGER, C. D. (2004). Issues, designs, and technical guidelines for adapting tests into multiple languages and cultures. In: HAMBLETON, R. K.; MERENDA, P. F.; SPIELBERGER, C. D (ed.). Adapting educational and psychological tests for cross-cultural assessment Mahwah: Psychology Press, 2004. p. 15-50

HERMOSILLA, D. et al. El liderazgo transformacional en las organizaciones: Variables mediadoras y consecuencias a largo plazo [Transformational leadership in organizations: Mediating variables and long-term consequences]. Journal of Work and Organizational Psychology, v. 32, n. 3, p. 135-143, 2016.

ILGEN, D. R. et al. Teams in organizations: From input-process-output models to IMOI models. Annu. Rev. Psychol., v. 56, p. 517-543, 2005.

ITURBIDE, L. M.; ELOSUA, P.; YANES, F. Medida de la cohesión en equipos deportivos. Adaptación al español del Group Environment Questionnaire (GEQ). Psicothema, v. 22, n. 3, p. 482-488, 2010.

JESUÍNO, J. C.; SOCZKA L.; MATOSO, J. G. Aferição de uma escala de atitudes para avaliação da satisfação no trabalho. Psicologia, v. 4, n. 1/2, p. 103-122, 1983.

KENT, T. W.; CROTTS, J. C.; AZZIZ, A. Four factors of transformational leadership behavior. Leadership \& Organization Development Journal, v. 22, n. 5, p. 221-229, 2001.

LIMA, S. M.; BRESSAN, C. L. (2003). Mudança organizacional: uma introdução. In: LIMA, S. M.; BRESSAN, C. L. Mudança organizacional: teoria e gestão. Rio de Janeiro: FGV, 2003. p. 17-63.

MACHADO, L. A. Liderança transformacional como componente da gestão de recursos humanos em organizações sociais. Revista Cientifica Da Faculdade De Educação E Meio Ambiente, v. 2, n. 1, p. 69-85, 2011.

MACIEL, C. DE O.; NASCIMENTO, M. R. Em busca de uma abordagem não atomizada para o exame das relações entre liderança transformacional e comprometimento organizacional. Revista de Administração (São Paulo), v. 48, n. 3, p. 544-559. 2013.

MAMEDE, C. et al. (2014). Leader's moral intelligence and employees' affective commitment: The mediating role of transformational leadership. JORNADAS LUSO ESPANHOLAS DE GESTÃ̃O CIENTÍFICA, 14, 2014, Leiria. Anais... Leiria: ESTGIPL, 2014. p. 1-10. Disponível em:

https://iconline.ipleiria.pt/bitstream/10400.8/3678/1/Mamede_Ribeiro_Gomes_Rego.pd f. Acesso em: 31 out. 2019. 
MCALLISTER, D. J. Affect-and cognition-based trust as foundations for interpersonal cooperation in organizations. Academy of management journal, v. 38, n. 1, p. 24-59, 1995.

MCNAIR, D. M.; LORR, M.; DROPPLEMAN, L. F. EdITS Manual for the Profile of Mood States. San Diego, CA: Educational and Industrial Testing Service, 1992.

MINAYO, M. C. O Desafio do conhecimento - pesquisa qualitativa em saúde. 14. ed. São Paulo: Hucitec, 2014. 407 p.

MUÑIZ, J.; ELOSUA, P.; HAMBLETON, R. K. Directrices para la traducción y adaptación de los tests: segunda edición. Psicothema, v. 25, n. 2, p. 151-157, 2013.

NEVES, L.G.; COIMBRA, J. L. Evidence of the Validity of the Internal Structure of the Ethical, Transformational and Moral Leadership Scale in an Educational Portuguese Context. Paidéia (Ribeirão Preto), v. 29, e2904. Epub February 04, 2019.

NEVES, L. et al. Estudo de adaptação e validação de uma escala de perceção de liderança ética para líderes portuguese. Análise Psicológica, v. 34, n. 2, p. 165-176, 2016.

OGBONNA, E.; HARRIS, L. C. Leadership style, organizational culture and performance: empirical evidence from UK companies. International Journal of Human Resource Management, v. 11, n. 4, p. 766-788, 2000.

OLVERA, J. et al. Transformational leadership and horizontal trust as antecedents of team performance in the healthcare context. Anales de Psicología, v. 33, n. 2, 365-375, 2017.

PARIS, L. Estrés laboral asistencial, recursos de afrontamiento y satisfacción laboral en trabajadores de la salud de la ciudad de Rosario. 2007. Tesis (Doctorado) Universidad Nacional de Rosario, Rosario, 2007.

PÉREZ SANTIAGO, J. A.; CAMPS DEL VALLE, V. Manifestación del Liderazgo Transformacional en un Grupo de Supervisores de Puerto Rico. Revista de Psicología del Trabajo y de las Organizaciones, v. 27, n. 1, p. 17-29, 2011.

PEPE, S. J. et al. Work Self-efficacy Scale and Search for Work Self-efficacy Scale: A validation study in Spanish and Italian cultural contexts. Revista de Psicología del Trabajo y de las Organizaciones, v. 26, n. 3, p. 201-210, 2010.

PERILLA-TORO, L. E.; GÓMEZ-ORTIZ, V. Relación del estilo de liderazgo transformacional con la salud y el bienestar del empleado: el rol mediador de la confianza en el líder. Revista de Psicología del Trabajo y de las Organizaciones, v. 33, n. 2, p. 95-108, 2017.

PESSOA, C. I. P. Liderança transformacional e eficácia grupal: o papel mediador da resiliência e dos comportamentos de suporte. 2016. Dissertação (Mestrado) Universidade de Coimbra, Coimbra, 2016.

PESSOA, C. I. P. et al. Liderança transformacional e a eficácia grupal: o papel mediador dos comportamentos de suporte. Estudos de Psicologia (Campinas), v. 35, n. 1, p. 15-28, 2018.

PODSAKOFF, P. M. et al. Transformational leader behaviors and their effects on followers' trust in leader, satisfaction, and organizational citizenship behaviors. The leadership quarterly, v. 1, n. 2, p. 107-142, 1990.

Revista Eletrônica Gestão e Serviços v.11, n. 2, pp. 3098 - 3129, Julho/Dezembro 2020. ISSN Online: 2177-7284 e-mail: regs@metodista.br 
PORTO, J. B.; TAMAYO, Á. Desenvolvimento e validação da escala de civismo nas organizações. Estudos de psicologia, v. 8, n. 3, p. 393-402, 2003.

PUCHEU, A. ¿Cómo el Liderazgo Transformacional de Supervisoras de Enfermería Afecta el Burnout de Enfermeras Clínicas?: Evidencia de dos Hospitales Chilenos. Ciencia \& Trabajo, v. 12, n. 38, p. 403-409, 2010.

QUIJANO, S. D.; NAVARRO CID, J. Un modelo integrado de la motivación en el trabajo: conceptualización y medida. Journal of Work and Organizational Psychology, v. 14, n. 2, p. 193-216, 1998.

RAFFERTY, A. E.; GRIFFIN, M. A. Dimensions of transformational leadership: Conceptual and empirical extensions. The leadership quarterly, v. 15, n. 3, 329-354, 2004.

RYFF, C. D. Happiness is everything, or is it? Explorations on the meaning of psychological well-being. Journal of personality and social psychology, v. 57, n. 6, p. 1069-1081, 1989.

RODRIGUES, A. DE O.; FERREIRA, M. C. The Impact of Transactional and Transformational Leadership Style on Organizational Citizenship Behaviors. Psico$U S F$, v. 20, n. 3, p. 493-504, 2015.

ROUSSEAU, V.; AUBÉ, C. Team self-managing behaviors and team effectiveness: The moderating effect of task routineness. Group \& Organization Management, v. 35, n. 6, p. 751-781, 2010.

ROZO-MOGOLLÓN, S.; ABAUNZA-GONZÁLEZ, M. Liderazgo transaccional y transformacional. Avances en Enfermería, v. 28, n. 2, p. 62-72, 2010.

SALANOVA, M.; LLORENS, S.; CIFRE, E.; MARTÍNEZ, I. M. We need a hero! Toward a validation of the healthy and resilient organization (HERO) model. Group \& Organization Management, v. 37, n. 6, p. 785-822, 2012.

SANDÍN, B. et al. Escalas PANAS de afecto positivo y negativo: validación factorial y convergencia transcultural. Psicothema, v. 11, n. 1, p. 37-51, 1999.

SCHILLING, J.; SCHILLING, E. Time of organisations, time for leadership: on the dynamics of leadership behaviours and time strategies. Business Leadership Review, v. 5, n. 2, p. 1-12, 2008.

SHAMIR, B. et al. Leadership and Social Identification in Military Units: Direct and Indirect Relationships 1. Journal of Applied Social Psychology, v. 30, n. 3, p. 612-640, 2000 .

SHOUKSMITH, G. A construct validation of a scale for measuring work motivation. New Zealand Journal of Psychology, v. 18, n. 2, p. 76-81, 1989.

SILVA BARRETO, L. M. T. et al. Cultura organizacional e liderança: uma relação possível?. Revista de Administração, v. 48, n. 1, 34-52, 2013.

SMITH, P. C.; KENDALL, L. M.; HULIN, C. L. The measurement of satisfaction in work and retirement: A strategy for the study of attitudes. Oxford, England: Rand Mcnally, 1969.

SOLANO, A. C. et al. Teoría y evaluación del liderazgo. Barcelona: Paidós, 2007.

STRAPASSON, M. R.; MEDEIROS, C. R. G. Liderança transformacional na

Revista Eletrônica Gestão e Serviços v.11, n. 2, pp. 3098 - 3129, Julho/Dezembro 2020. ISSN Online: 2177-7284 e-mail: regs@metodista.br 


\section{SOARDO; FANTON; JUNIOR}

enfermagem. Revista Brasileira de Enfermagem, v. 62, n. 2, p. 228-233, 2009.

VAN DIERENDONCK, D. The construct validity of Ryff's Scales of Psychological Well-being and its extension with spiritual well-being. Personality and individual differences, v. 36, n. 3, p. 629-643, 2004.

VÁZQUEZ-ALATORRE, A. Interdependencia entre el liderazgo transformacional, cultura organizacional y cambio educativo: una reflexión. REICE. Revista Iberoamericana sobre Calidad, Eficacia y Cambio en Educación, v. 11, n. 1, p. 73-91, 2013.

VEGA, C.; ZABALA, G. Adaptación del Cuestionario Multifactorial de Liderazgo MLQ Forma 5X Corta- de B. Bass y B. Avolio al Contexto Organizacional Chileno. 2004. Tesis (Maestría) - Universidad de Chile, Santiago de Chile, 2004.

VIANA, M. F.; ALMEIDA, P. L.; SANTOS, R. C. Adaptação portuguesa da versão reduzida do perfil de estados de humor. Análise Psicológica, v. 19, n. 1, p. 77-92, 2001.

VIZEU, F. Uma aproximação entre liderança transformacional e Teoria da Ação Comunicativa. RAM. Revista de Administração Mackenzie, v. 12, n. 1, p. 53-81, 2011.

WEYMER, A.; MOREIRA, V. O Papel da Liderança Transformacional na Reconstrução de Significados Compartilhados de uma Unidade Estratégica de Negócios da Área da Saúde. Revista de Gestão em Sistemas de Saúde, v. 6, n. 1, p. 23-31, 2017.

i Modelo de liderança no qual o líder pouco interfere nas decisões da equipe, isentando-se da resolução de conflitos e do esclarecimento quanto as suas expectativas quanto aos liderados e deixando as decisões a critério dos liderados (BASS; AVOLIO, 2000).

ii Segundo o portal de notícias de saúde do Hospital Israelita Albert Einstein (https://www.einstein.br/estrutura/check-up/saude-bem-estar/saude-mental/sindrome-burnout), Burnout é um transtorno de ordem psicológica relacionado ao estresse excessivo, advindo da atividade laboral. Chamada de Síndrome de Burnout, caracteriza-se essencialmente por exaustão prolongada e diminuição de interesse no trabalho. O indivíduo pode apresentar sintomas físicos e psicológicos como: dores musculares, cansaço, apatia, desânimo, entre outros. 